\title{
A cross sectional observational study to estimate herd level risk factors for Leptospira spp. serovars in small holder dairy cattle farms in southern Chile
}

Miguel Salgado ${ }^{1 *}$, Barbara Otto ${ }^{1}$, Errol Sandoval ${ }^{1}$, German Reinhardt ${ }^{1}$ and Sofia Boqvist ${ }^{2}$

\begin{abstract}
Background: The south of Chile constitutes the main cattle milk producing area of the country. Regarding leptospirosis control in Chile, there is neither an official program nor an epidemiological characterization of smallholder dairy farms. This study was carried out to determine Leptospira seroprevalence and to evaluate risk factors associated with seropositivity at herd level in smallholder bovine dairy herds in southern Chile.

A cross-sectional study was conducted, and a convenient sample of 1,537 apparently healthy dairy cows was included in the study. Individual blood samples were taken and examined for six selected reference Leptospira serovars by the Microscopic Agglutination Test (MAT).

Results: Of the included herds 75\% (52/69) showed serological titers against one or more Leptospira serovar. Leptospira borgpetersenii serovar Hardjo was the serovar most frequently (81\%) reported from animals with positive results. The variables considered risk factors for Leptospira seropositivity were calve natural breeding system, using a specific calving area and vaccination against Leptospira. Adult cows in contact with calves weaned, proved to be a protective factor against infection.
\end{abstract}

Conclusions: Herds neglecting the management practices mentioned in this study could represent an important source of Leptospira infection for other herds in the same geographic area, as well as for other animal species.

Keywords: Leptospira, Seropositivity, MAT, linfection, Risk factors, Herd

\section{Background}

Leptospirosis is considered one of the important zoonoses with a worldwide distribution. It is most prevalent in countries with subtropical or tropical climates since leptospires survive better in warm and wet environments [1-3]. Leptospirosis has been considered an occupational disease; however globalization, climate change and human migration to new areas have placed human populations at risk [4]. The infection has also been established as one of the most important infectious diseases in livestock, particularly in cattle, due to negative impacts on reproduction (abortion, embryonic death, stillbirths and infertility), decreased milk production and growth rates, as well as indirect costs associated with treatments [5-8].

\footnotetext{
*Correspondence: miguelsalgado@uach.cl

'Department of Biochemistry and Microbiology, Faculty of Sciences, Universidad Austral de Chile, Edificio Instapanel, Campus Isla Teja, CC 567 Valdivia, Chile

Full list of author information is available at the end of the article
}

The bacterial agent, Leptospira is divided into serogroups, which in turn are divided into serovars based on their antigenic differences [5].

Leptospira infection in Chile is present both in domestic and wild animals [9-11] and does therefore constitute a public health risk. However, a mandatory official record of this disease in humans was not established until 2002 together with a diagnostic surveillance system. From that date, the annual incidence rate has been estimated to range from 0.02 to 0.18 per hundred thousand inhabitants per year [12]. Several studies have been conducted to estimate leptospiral seropositivity in some selected animal populations such as cattle (59 to $91 \%$ ), swine $70 \%$, horses (49\%) wild mice (47\%), goats (24\%) and sheep (7\%) [11].

In areas with similar climatic conditions and herd management practices such as Chile, factors such as herd size, replacement policy, herd type, access to contaminated water sources, introduction of other animals, presence of veterinary assistance, and different domestic 
ruminants co-grazing, are possibly associated with seropositivity against Leptospira and herd infection status [7,13-15]. Herd-level factors associated with the risk of a herd being seropositive have shown a significant impact not only on the overall seroprevalence of leptospirosis, but also on the serovar distribution [13].

The south of Chile constitutes the main milk producing area of the country; $80 \%$ of the dairy herds producing $66 \%$ of the total Chilean milk yield. A significant number of the dairy farms in Chile are classified as subsistence farms, corresponding to $84 \%$ of the 11,000 dairy farms in this geographical area [16,17].

Regarding leptospirosis control in Chile, there is neither an official program nor an epidemiological characterization of smallholder dairy farms, and no previous studies have reported Leptospira seroprevalence or risk factors for seropositivity or active Leptospira infection in these types of herds. This study was carried out to determine Leptospira seroprevalence and to evaluate risk factors associated with seropositive results in smallholder bovine dairy herds in southern Chile.

\section{Methods}

\section{Study population and study design}

A cross-sectional study was conducted among smallholder dairy farms in De Los Ríos region, southern Chile, between January and April 2011. These are subsistence farmers that produce $<100,000 \mathrm{~kg}$ of milk per year $[16,17]$. The cattle graze outside all-year round and are fed little or no concentrates. Traditionally, milk was collected by hand and transported to a local co-operative milk collection centre where it was added to milk from other farms and cooled in a large refrigerated tank. At the time of the study, it was mandatory for each farm to have its own milking machine and milk bulk tank. The study population comprised more than 2,000 animals from 69 dairy herds. A convenient sample of 1,537 apparently healthy dairy cows was included in the study. In most of the herds, all lactating cows were sampled.

\section{Serum collection}

Individual blood samples $(5-10 \mathrm{ml})$ were obtained, under owners' consent for the collection of samples, by venipuncture from the coccygeal vein using the Vacutainer system, in strict accordance with the recommendations in the Guide of Use of Animals for Research of Universidad Austral de Chile, approved by the Committee on the Ethics of Animals for Research (www.uach.cl/direccion/ investigacion/uso_animales.htm). All samples were kept at room temperature until transfer to the Department of Biochemistry and Microbiology, Faculty of Sciences, Universidad Austral de Chile, Valdivia. In the laboratory, blood samples were kept at room temperature until centrifugation and removal of serum. The serum samples were kept at $-20^{\circ} \mathrm{C}$ until analysis.

\section{Collection of epidemiological data}

Information on management and housing factors was collected from the owner or person in charge of each herd using a written questionnaire with open and closed questions, after getting oral consent. The questionnaire was designed to obtain information on variables regarded as potential risk factors for Leptospira seropositivity defined by serological titres $\geq 1$ : 100 as well as for Leptospira infection defined by serological titres $\geq 1$ : 400 [18]. The questions were related to presence of domestic and wild animals sharing pasture with cattle, presence of dogs, history of clinical cases of leptospirosis in the herd, Leptospira vaccination (on a yearly basis), purchase and introduction of animals (within the last five years), presence of a specific calving area, cleaning of the calving area, system of calf rearing (natural or sucking method versus artificial or weaning method), adult cattle in contact with calves and heifers, abortion events (during the last five years), contact with neighboring animals, and presence of rodent control.

\section{Leptospira serology}

The sera were examined for antibodies against six selected reference Leptospira serovars (Table 1) using the Microscopic Agglutination Test (MAT) [18]. The antigens used consisted of serovars known to be present in the study area and to be of clinical importance [10,19].

All sera that gave a positive reaction at 1:100 screening dilution were titrated in serial twofold dilutions to titre end-point of 1:400. A titre of 1:100-1:200 was considered a low positive titre, and interpreted as indicating exposure to leptospirae. Titres $\geq 1: 400$ were considered to be highpositive titres, and were interpreted as indicating either recent or active infection [18].

\section{Statistics}

Statistical analyses were performed using SAS version 9.2 (Cary NC, USA). The dependent variable was event/trial, in this case number of seropositive animals per herd/number of sampled animals per herd. All analyses were performed using the glimmix procedure. Two sets of analyses were conducted; one using a titer cut-off of 1:100 and the other 1:400. Univariable analyses were initially performed to investigate the association between Leptospira seropositivity and each of the explanatory variables (Table 2). All variables with a $p$-value $\leq 0.25$ were included in a multivariable regression model. In the analysis using a titer of $1: 100$ the following variables showed a p-values $\leq 0.25$ : use of designated calving area, cleaning designated calving area, calf rearing system, adult cows in contact with calves, adult cows in contact with heifers, horses on the farm, rodent control, sheep and/or goats present on the farm and 
Table 1 Leptospira interrogans and Leptospira borgpetersenii serovars used as antigens in the microscopic agglutination test for serological analyses of bovine leptospirosis in a study among dairy cows in Chile 2011

\begin{tabular}{lccc}
\hline Species & Serogroup & Serovar & Strain \\
\hline Leptospira interrogans & autumnalis & Autumnalis & Akiyami A \\
Leptospira borgpetersenii & ballum & Ballum & Mus 127 \\
Leptospira interrogans & canicola & Canicola & Hond Utrecht IV \\
Leptospira interrogans & icterohaemorrhagiae & Icterohaemorrhagiae & Icterohaemorrhagiae \\
Leptospira interrogans & pomona & Pomona & Pomona \\
Leptospira borgpetersenii & sejroe & Hardjo & Ar \\
\hline
\end{tabular}

Table 2 Cross classification of biosecurity or management variables and serological Leptospira results using the microscopic agglutination test at herd level using a cut-off level of 1:100 among 69 dairy herds in southern Chile, 2011

\begin{tabular}{|c|c|c|c|}
\hline \multirow[t]{2}{*}{ Variables } & \multirow[t]{2}{*}{ Category } & \multicolumn{2}{|c|}{ MAT results } \\
\hline & & No. seropos (\%) & No. seroneg (\%) \\
\hline \multirow[t]{2}{*}{ Abortions } & yes & $18(26)$ & $5(7.2)$ \\
\hline & no & $34(49)$ & $12(17)$ \\
\hline \multirow[t]{2}{*}{ Adult cows in contact with calves } & yes & $27(39)$ & $10(14)$ \\
\hline & no & $25(36)$ & $7(10)$ \\
\hline \multirow[t]{2}{*}{ Adult cows in contact with heifers } & yes & $34(49)$ & $9(13)$ \\
\hline & no & $18(26)$ & $8(12)$ \\
\hline \multirow[t]{2}{*}{ Calve rearing system } & natural & $25(36)$ & 11(16) \\
\hline & artificial & $27(40)$ & $6(8.7)$ \\
\hline \multirow[t]{2}{*}{ Cleaning the designated calving area } & yes & $5(7.2)$ & $4(5.8)$ \\
\hline & no & $47(68)$ & $13(8.7)$ \\
\hline \multirow[t]{2}{*}{ Horses on the farm } & yes & $12(17)$ & $1(1.5)$ \\
\hline & no & $40(58)$ & $16(23)$ \\
\hline \multirow[t]{2}{*}{ Leptospira vaccination } & yes & $3(2.1)$ & $0(0)$ \\
\hline & no & $49(33)$ & $17(25)$ \\
\hline \multirow[t]{2}{*}{ Pigs on the farm } & yes & $15(22)$ & $4(5.8)$ \\
\hline & no & $37(54)$ & $13(19)$ \\
\hline \multirow[t]{2}{*}{ Presence of dogs } & yes & $43(62)$ & $11(16)$ \\
\hline & no & $9(13)$ & $6(8.7)$ \\
\hline \multirow[t]{2}{*}{ Purchase and/or introduction of new cattle } & yes & $31(45)$ & $9(13)$ \\
\hline & no & $21(30)$ & $8(12)$ \\
\hline \multirow[t]{2}{*}{ Rodent control } & yes & $39(57)$ & $12(17)$ \\
\hline & no & $13(19)$ & $5(7.2)$ \\
\hline \multirow[t]{2}{*}{ Rodents on the farm } & yes & $39(57)$ & $7(10)$ \\
\hline & no & $13(18)$ & $10(15)$ \\
\hline \multirow[t]{2}{*}{ Sheep or goats on the farm } & yes & $11(16)$ & $5(7.3)$ \\
\hline & no & $41(59)$ & $12(17)$ \\
\hline \multirow[t]{2}{*}{ Use of designated calving area } & yes & $33(48)$ & $4(5.6)$ \\
\hline & no & $19(28)$ & $13(19)$ \\
\hline \multirow[t]{2}{*}{ Wild boars } & yes & $8(12)$ & $1(1.4)$ \\
\hline & no & $44(64)$ & $16(23)$ \\
\hline
\end{tabular}


leptospira vaccination. For the analysis using a cut off of 1:400 the variables cleaning a designated calving area, calf rearing system, horse on the farm and leptospira vaccination showed a p-value $\leq 0.25$. Manual backward elimination of variables with p-values $\geq 0.05$ was performed until all remaining variables showed a $p$-value of $\leq 0.05$. The models were investigated for interactions and confounders. A confounder was defined as a variable changing the point estimates of the included explanatory variables by more than $25 \%$. The variable herd was included as a random effect to correct for over dispersion.

\section{Results}

\section{Descriptive results}

The mean number of sampled dairy cattle per herd was 22 , with a range from 3 to 84 . All the study herds showed the same semi-extensive milking type system, co-habiting with other farm animals. All cattle in the herds were apparently healthy, showing no reproductive or production problems. Only $11 \%$ of the herds had a history of suspected clinical leptospirosis presumptively diagnosed by necropsy and there was no history of vaccination against Leptospira during the last five years. However, $4.3 \%$ of the herds reported vaccination more than 5 years ago. In all but one herd, cattle coexisted on pasture together with other domestic and wild animals, such as hare, fox, puma, wild boar, pudu and mink. A high proportion of herds (78\%) had dogs and also reported the presence of rodents on their premises (67\%). Fifty eight percent of the herd owners defined themselves as having open herds, and they allowed entry of new animals to their farms. More than half (54\%) of the herds had a specific calving area, but few of them (13\%) routinely cleaned this area. An almost equal number of herds used either a natural or an artificial calf rearing system. An important proportion of herd owners (54\%) confirmed that adult cattle had direct contact with calves and heifers (Table 2).

\section{Serological results}

Of the included herds $75 \%$ (52/69) showed positive results for one or more Leptospira serovars using a cut off value of $\geq 1: 100$. Out of those herds $63 \%(n=33)$ had at least one individual with a titer suggesting active infection ( $\geq 1: 400)$. Overall, 21\% (320/1,537) and 8\% (128/ $1,537)$ of included dairy cows showed titers of $\geq 1: 100$ and $\geq 1: 400$, respectively, for at least one of the $L$. interrogans and $L$. borgpetersenii serovars (Table 3 ). Within each herd, the frequency of seropositive dairy cows ranged from $2 \%$ to $75 \%$, with a median of $15 \%$.

Leptospira borgpetersenii serovar hardjo was the serovar most frequently reported from animals with positive serological results independent of the cut-off value being used (Table 3).

\section{Risk factors for leptospira seropositivity and infection}

The variables considered risk factors in the multivariable model for Leptospira seropositivity, using a cut-off value of 1:100 were, using natural calve rearing vs artificial $(\mathrm{P}=0.006$; Odds Ratio $=3.0)$ (Table 4) and using a designated calving area $(\mathrm{P}=0.05 ; \mathrm{OR}=1.9)$. Another factor associated with Leptospira seropositivity was vaccination ( $\mathrm{P}=0.0001$; $\mathrm{OR}=6.5$ ). Adults cows in contact with calves had no association $(\mathrm{P}=0.007$; $\mathrm{OR}=1.1)$. No interactions or confounders were found in the model. There were no significant variables in the model associated with titres $>=1: 400$.

\section{Discussion}

This is the first risk factor study of leptospiral seropositivity in small holder cattle herds in southern Chile. Despite constituting more than $80 \%$ of the milk herds in the country $[16,17]$, the milk production of these herds makes up less than $20 \%$ of the milk produced and industrialized in Chile. Given the significant number of small holder cattle herds in the country, this risk factor study was carried out in order to gather more in-depth information on these herds, including details of husbandry practices that possibly favor Leptospira transmission both within and between herds.

The high frequency of herds $(75 \%)$ with at least one MAT-positive animal demonstrates the wide distribution of Leptospira infection in the smallholder cattle population

Table 3 Seroprevalence of Leptospira serovars at and different titre levels determined by the microscopic agglutination test among 69 dairy herds in southern Chile, 2011

\begin{tabular}{|c|c|c|c|c|c|}
\hline Serovar & 1:100 & $1: 200$ & $\geq 1: 400$ & Total & Total \% \\
\hline Leptospira borgpetersenii serovar Hardjo & 81 & 61 & 118 & 260 & 81.25 \\
\hline Leptospira interrogans serovar Pomona & 20 & 8 & 7 & 35 & 10.94 \\
\hline Leptospira interrogans serovar Autumnalis & 10 & 3 & 2 & 15 & 4.7 \\
\hline Leptospira interrogans serovar Canicola & 2 & 2 & 1 & 5 & 1.6 \\
\hline Leptospira interrogans serovar Icterohaemorrhagiae & 2 & 1 & 0 & 3 & 0.94 \\
\hline Leptospira interrogans serovar Ballum & 2 & 0 & 0 & 2 & 0.63 \\
\hline Total & 117 & 75 & 128 & 320 & 100 \\
\hline
\end{tabular}


Table 4 Significant management and biosecurity variables considered risk factors in a multivariable logistic regression for Leptospira seropositivity using a cut off of 1:100 among 69 dairy herds in southern Chile, 2011

\begin{tabular}{lccc}
\hline Variable & $\boldsymbol{\beta}$ & $\mathbf{p}$-value & OR (95\% Cl) \\
\hline Using natural calve rearing vs. artificial & 0.11 & 0.006 & $3.0(1.4-6.3)$ \\
Using designated calving area & 0.63 & 0.05 & $1.9(0.98-3.5)$ \\
Adult cows in contact with calves & -1.1 & 0.007 & $0.34(0.16-0.74)$ \\
Leptospira vaccination & 1.9 & 0.0001 & $6.5(2.2-19)$ \\
\hline
\end{tabular}

in southern Chile. This seroprevalence is higher than the 43\% and 53\% found by Alonso-Andicoberry et al. [7] and Subharat et al. [15], respectively, in Chilean cattle herds. It is similar, though, to the $82 \%$ in unvaccinated suckler herds reported by Ryan et al. [14], where calves were reared with infected dams, just as is the case in the present study.

Although the MAT is a serological diagnostic screening test, it is considered confirmatory if animals have titers $\geq 1: 400$ [18]. Out of 320 positive samples, $128(40 \%)$ showed antibody titers equal to or greater than 1:400, which suggests an important active infection transmission process in the animal population under study.

The most prevalent Leptospira serovar found in this study was Leptospira borgpetersenii serovar Hardjo. This is consistent with what has been presented previously in the literature, both nationally and internationally [6,10,19-22] . Although, southern Chile, with its abundant grassland and moderate temperatures, is an ideal environment for Leptospira survival $[14,23,24]$ it is suggested that infected cattle act as the main reservoir for Leptospira borgpetersenii serovar Hardjo, independently of favourable climatic conditions [7]. However, poor biosecurity practices can lead to increased risk and perpetuation of the infectious agent and thus the onset of infection in the herd. In the present study, this was reflected by the finding that use of natural calf rearing vs. artificial and a designated calving area was shown to be a risk factor for seropositivity.

In this study a high percentage of the animals showed titers above1:400 (40\%). This suggests that Leptospira borgpetersenii serovar Hardjo is adapted to cattle as high titres are expected after active infections [8].

A large proportion of herd owners (52\%) confirmed that they used a natural calf raising system, allowing the lactating cattle to meet their calves (from birth to weaning after 6-8 months). Close contact between an infected and a susceptible animal, as in the natural calf raising system, in the author's opinion, should be considered as the most important variable influencing the herd's infection status in southern Chile dairy herds. This is consistent with findings reported elsewhere on transmission of infections in cattle herds, where herd level factors related with close contact such as co-grazing between infected and susceptible hosts, access to contaminated water sources and introduction of other animals showed association with leptospirosis herd infection status [13].

In most cases, the calving area was defined as a small paddock beside the owner's home. Using this heavily overcrowded calving area increased the likelihood of cattle being seropositive, suggesting high levels of Leptospira transmission. A simple interpretation indicates that this variable in itself should not be considered a risk factor as the majority (77\%) of the positive herds did not report any practice of cleaning the calving area. The improper hygienic maintenance of the calving area, such as urine shedding of leptospires and accumulation of leptospira contaminated fetal tissue and placentae may lead to an increased risk for infection. This is one plausible explanation for the significant association between calving area and Leptospira seropositivity. This is true especially during the rainy season when the humidity is high. All these factors combined create an environment that enhances the survival of these bacteria.

\section{Conclusions}

This study demonstrated that a high proportion of herds in small dairy farms in southern Chile tested Leptospira positive. Together with vaccination and antibiotic therapy, specific preventive measures in husbandry practices should be implemented to control Leptospira transmission. Herds neglecting the management practices mentioned in this study could represent an important source of Leptopira infection for other herds in the same geographic area, as well as for other animal species.

\section{Ethics}

The present study was carried out in strict accordance with the recommendations in the Guide of Use of Animals for Research of Universidad Austral de Chile (www.uach. cl/direccion/investigacion/uso_animales.htm).

\section{Competing interest}

The authors declare competing interest neither competing nor financial.

\section{Authors' contributions}

MS: design of the study, lab work and draft writing; BO design of the study; ES: lab work and draft writing; GR: design of the study; SB: design of the study, data analysis and draft writing. All authors read and approved the final manuscript.

\section{Acknowledgments}

This work was supported by DID GRANT S-2012-19.

\section{Author details}

Department of Biochemistry and Microbiology, Faculty of Sciences, Universidad Austral de Chile, Edificio Instapanel, Campus Isla Teja, CC 567 Valdivia, Chile. ${ }^{2}$ Department of Biomedical Sciences and Veterinary Public Health, Swedish University of Agricultural Sciences, Box 7028, SE-750 07 Uppsala, Sweden.

Received: 10 November 2013 Accepted: 21 May 2014

Published: 6 June 2014 


\section{References}

1. Levett PN: Leptospirosis. Clin Microbiol Rev 2001, 14:296-326.

2. Thiermann AB: Leptospirosis: current developments and trends. J Am Vet Med Assoc 1984, 184:722-725.

3. Vijayachari P, Sugunan AP, Shriram AN: Leptospirosis: An emerging global, public Health problem. J Biosci 2008, 33:557-569.

4. Bharti A, Nally JE, Ricaldi JN, Matthias MA, Diaz MM, Lovett MA: Leptospirosis: A zoonotic disease of global importance. Lancet Infect Dis 2003, 3(12):757-771

5. Adler B, de la Peña MA: Leptospira and Leptospirosis. Vet Microbiol 2010 27:287-296

6. Aguiar DM, Gennari MS, Cavalcante TG, Labruna MB, Vasconcellos SA, Rodrigues AR, Oraes ZM, Camargo LM: Seroprevalence of Leptospira spp in cattle from Monte Negromunicipality, western Amazon. Pesq Vet Bras 2006, 26:102-104.

7. Alonso-Andicoberry C, García-Peña FJ, Pereira-Bueno J, Costas E, Ortega-Mora LM: Herd-level risk factors associated with Leptospira spp. Seroprevalence in dairy and beef cattle in Spain. Prev Vet Med 2001, 52:109-117.

8. Ellis WA: Leptospirosis as a cause of reproductive failure. Vet Clin North Am 1994, 10:463-478.

9. Riedemann S, Cabezas X, Zamora J: Detección de aglutininas antileptospira en sueros de roedores silvestres del área rural de Valdivia. Av Cs Vet 1994, 9:162-164.

10. Zamora J, Riedemann S, Montesinos M, Cabezas X: Aislamiento en Chile de Leptospira interrogans serovares hardjo y kennewicki en bovinos aparentemente sanos. Arch Med Vet 1991, 23:131-134.

11. Zamora J, Riedemann S: Animales silvestres como reservorios de Leptospirosis en Chile. Una revisión de los estudios efectuados en el país. Arch Med Vet 1999, 31:151-156.

12. Zunino E, Pizarro R: Leptospirosis. Puesta al día. Rev Chil Infect 2007, 24:220-226.

13. Lilenbaum W, Santos MR: Effect of management systems on the prevalence of bovine leptospirosis. Vet Rec 1996, 138:570-571.

14. Ryan EG, Leonard N, O'Grady L, Doherty ML, More SJ: Herd-level risk factors associated with Leptospira Hardjo seroprevalence in Beef/Suckler herds in the Republic of Ireland. Ir Vet J 2012, 65:6-15.

15. Subharat S, Wilson PR, Heuer C, Collins-Emerson JM: Longitudinal serological survey and herd-level risk factors for Leptospira spp. serovars Hardjo-bovis and Pomona on deer farms with sheep and/or beef cattle. New Zeal Vet J 2012, 60:215-222.

16. Amtmann C, Mujica F, Vera B: Producción de Leche. In Pequeña Agricultura de la Región de los Lagos, Valdivia, Chile; 1995:75-91.

17. CHILE: VII Censo Nacional Agropecuario y Forestal. Santiago, Chile: Instituto Nacional de Estadísticas, Ministerio de Economía; 2007.

18. Faine S, Adler B, Bolin C, Perolat P: Leptospira and Leptospirosis. Melbourne, Australia: Medisci Press; 1999:131-143.

19. Riedemann S, Leal H, Zamora J: Diagnostico serológicos de Leptospirosis bovina en cuatro regiones de Chile. Arch Med Vet 1986, 18:129-133.

20. Collares-Pereira M: Bovine leptospirosis in cattle in Portugal: bacteriological and serological findings. Vet Rec 1991, 128:549-550.

21. Rocha T: A review of leptospirosis in farm animals in Portugal. Rev Sci Tech Off Int Epiz 1998, 17:699-712.

22. Schoonman L, Swai ES: Herd and animal level risk factors for bovine leptospirosis in Tanga región of Tanzania. Trop Animal Health Prod 2010, 42:1565-1572.

23. Elder JK, McKeon GM, Duncalfe F, Ward WH, Leutton RD: Epidemiological studies on the ecology of Leptospira interrogans serovars Pomona and Hardjo in Queensland. Prev Vet Med 1986, 3:501-521.

24. Wikse SE, Rogers GM, Ramachandran S, Engelken TJ, Epperson WB, Larson RL, Maas J, Richey E, Bolin C: Herd Prevalence and Risk Factors of Leptospira Infection in Beef Cow/calf Operations in the United States: Leptospira borgpetwerseni Serovar Hardjo. Bovine Practitioner 2007, 41:15-23.

doi:10.1186/1746-6148-10-126

Cite this article as: Salgado et al:: A cross sectional observational study to estimate herd level risk factors for Leptospira spp. serovars in small holder dairy cattle farms in southern Chile. BMC Veterinary Research 2014 10:126.

\section{Submit your next manuscript to BioMed Central and take full advantage of:}

- Convenient online submission

- Thorough peer review

- No space constraints or color figure charges

- Immediate publication on acceptance

- Inclusion in PubMed, CAS, Scopus and Google Scholar

- Research which is freely available for redistribution

Submit your manuscript at www.biomedcentral.com/submit
C Biomed Central 